\title{
A randomised multicentre phase II study with cisplatin/docetaxel vs oxaliplatin/ docetaxel as first-line therapy in patients with advanced or metastatic non-small cell lung cancer
}

\begin{abstract}
A Atmaca*,1 , S-E Al-Batran ${ }^{1}$, D Werner ${ }^{1}$, C Pauligk ${ }^{1}$, T Güner ${ }^{1}$, A Koepke ${ }^{1}$, H Bernhard ${ }^{2}$, T Wenzel $^{2}$, A-G Banat ${ }^{3,4}$, P Brueck ${ }^{4}, \mathrm{~K} \mathrm{Caca}^{5}$, N Prasnikar ${ }^{5}, \mathrm{~F} \mathrm{Kullmann}^{6}, \mathrm{H}$ Günther Derigs ${ }^{7}, \mathrm{M} \mathrm{Koenigsmann}^{8}$, G Dingeldein ${ }^{9}$, T Neuhaus $^{10}$ and E Jäger ${ }^{1}$
\end{abstract}

${ }^{1}$ Department of Hematology and Oncology, Institute of Clinical Research (IKF) at Krankenhaus Nordwest, UCT-University Cancer Center, 60488 Frankfurt am Main, Germany; ${ }^{2}$ Department of Internal Medicine IV-Oncology and Hematology, Klinikum Darmstadt, 64283 Darmstadt, Germany; ${ }^{3}$ Department of Internal Medicine, Gesundheitszentrum Wetterau, 61231, Bad Nauheim, Germany; ${ }^{4}$ Department of Hematology and Oncology, Justus Liebig University Hospital, 35390 Giessen, Germany; ${ }^{5}$ Department of Internal Medicine-Gastroenterology, Haemato-Oncology, Diabetology and Infectiology, Klinikum Ludwigsburg, 71640 Ludwigsburg, Germany; ${ }^{6}$ Department of Internal Medicine I, Klinikum Weiden, 92637 Weiden, Germany; ${ }^{7}$ Department of Internal Medicine III, Hematology and Oncology, Klinikum Frankfurt Hoechst, 65929 Frankfurt am Main, Germany; ${ }^{8}$ Schwerpunktpraxis und Tagesklinik für Hämatologie-Onkologie, 30171 Hannover, Germany; ${ }^{9}$ Onkologische Schwerpunktpraxis, 64295 Darmstadt, Germany;

${ }^{10}$ Department of Hematology and Oncology, St Vincenz Krankenhaus, 65549 Limburg, Germany

Background: This study was designed to compare cisplatin/docetaxel with oxaliplatin/docetaxel in patients with advanced and metastatic non-small lung cancer as a first-line treatment.

Methods: Patients were randomly assigned to receive either cisplatin $75 \mathrm{mg} \mathrm{m}^{-2}$ and docetaxel $75 \mathrm{mg} \mathrm{m}^{-2}$ every 3 weeks or oxaliplatin $85 \mathrm{mg} \mathrm{m}^{-2}$ and docetaxel $50 \mathrm{mg} \mathrm{m}^{-2}$ every 2 weeks. The primary end point was response rate, and secondary end points were toxicity, time to progression and overall survival.

Results: A total of 88 patients (median age: 65 (39-86) years; stage IV: 93\%) were randomly assigned. Response rate (complete and partial response) was $47 \%$ (95\% Cl: 33-61\%) in the cisplatin/docetaxel arm and 28\% (95\% Cl: 17-43\%) in the oxaliplatin/docetaxel $\operatorname{arm}(P=0.118)$. There was no significant difference in time to progression (6.3 vs 4.9 months, $P=0.111)$ and median overall survival (11.6 vs 7.0 months, $P=0.102$ ) with cisplatin/docetaxel vs oxaliplatin/docetaxel, although slight trends favouring cisplatin were seen. Oxaliplatin/docetaxel was associated with significantly less (any grade) renal toxicity (56\% vs $11 \%$ ), any grade fatigue ( $81 \%$ vs $59 \%$ ), complete alopecia ( $76 \%$ vs $27 \%$ ), any grade leukopenia ( $84 \%$ vs $61 \%$ ) and grade $3 / 4$ leukopenia (44\% vs $14 \%$ ) and neutropenia (56\% vs $27 \%)$.

Conclusion: Oxaliplatin/docetaxel has activity in metastatic non-small cell lung cancer, but it seems to be inferior to cisplatin/ docetaxel.

*Correspondence: Dr A Atmaca; E-mail: atmaca.akin@khnw.de

Received 2 August 2012; revised 15 November 2012; accepted 20 November 2012; published online 17 January 2013

(c) 2013 Cancer Research UK. All rights reserved 0007-0920/13 
Despite encouraging efforts towards individualised and targeted therapies (Mok et al, 2009) in advanced non-small cell lung cancer (NSCLC), platinum-containing combinations still represent the standard of care for the majority of patients.

Cisplatin is widely used and is accepted as the most efficacious platin compound; however, its use is limited by its toxicity profile, especially nausea/vomiting and nephrotoxicity. In addition, the complexity of cisplatin administration prohibits the use in a substantial proportion of patients, particularly elder patients and those with relevant comorbidities.

Although carboplatin seems to be an alternative to cisplatin, there is still a debate about the inferiority of carboplatin in terms of response rate (Rosell et al, 2002), progression and overall survival, deriving from several meta-analyses or head-to-head comparisons (Ardizzoni et al, 2007). Furthermore, carboplatin has a relevant haematologic toxicity profile when used in equipotent dosages.

In metastatic lung cancer, survival is modestly improved with platinum-based palliative chemotherapy, but, more important it can help to reduce tumour-related symptoms, and lead to improved quality of life (QoL). Hence, response often correlates with improved QoL, especially in patients with tumour-related symptoms (Fosella et al, 2003). On the other hand, chemotherapyassociated toxicity can overweigh the benefits resulting from tumour response. Therefore, there is enormous need to improve tolerability of chemotherapy without loss of efficacy.

Oxaliplatin, a third-generation platinum compound, proved to be effective in colorectal and gastric cancer, and has a favourable toxicity profile as compared with cisplatin (Al-Batran et al, 2008a). Furthermore, oxaliplatin can be safely given in an outpatient setting without need for specific hydration treatment.

In the first-line treatment of advanced NSCLC, oxaliplatin has been shown to have promising efficacy and a favourable toxicity profile in combination with pemetrexed (Scagliotti et al, 2005), gemcitabine (Bidoli et al, 2007) or docetaxel (Raez et al, 2006).

Based on these data, we designed this open-label, randomised, multicentric, phase II study to evaluate the efficacy and tolerability of oxaliplatin/docetaxel (Ox/Doc) in comparison with cisplatin/ docetaxel (Cis/Doc) in stage IIIB/IV NSCLC.

\section{MATERIALS AND METHODS}

Patient eligibility. Patients with histologically confirmed stage IIIB or IV (UICCC 6) NSCLC were eligible. Further criteria were as follows: no prior palliative chemotherapy, measurable target lesion, age over 18 years, Eastern Cooperative Oncology Group performance status $\leqslant 2$, sufficient bone marrow function, creatinine clearance $>45 \mathrm{ml} \mathrm{min}^{-1}$ or serum creatinine $\leqslant 1.25 \mathrm{ULN}$, no concurrent uncontrolled medical illness and no other current or previous malignancy within the past 5 years (with the exception of squamous-cell carcinoma of the skin treated by surgery). Patients were excluded from the study if they had received neoadjuvant or adjuvant chemotherapy within the past 6 months; radiation therapy within the past 28 days; peripheral neuropathy of National Cancer Institute grade $\geqslant 2$ at baseline; significant weight loss ( $>10 \%$ body weight in the preceding 6 weeks); brain metastases; inflammatory bowel disease; cardiomyopathy or cardiac insufficiency (New York Heart Association classification of heart disease class II to IV); known hypersensitivity to cisplatin, oxaliplatin or docetaxel; or were pregnant or breast-feeding. Women of childbearing potential were advised to take adequate precautions to prevent pregnancy. Written informed consent was obtained from all patients. The study was approved by the ethics committees of the participating institutions.

Treatment. Patients were stratified by centre and performance status and were randomly assigned to either cisplatin/docetaxel (arm A) or oxaliplatin/docetaxel (arm B). Patients in the arm A received cisplatin $75 \mathrm{mg} \mathrm{m}^{-2}$ as a 2 -h infusion and docetaxel $75 \mathrm{mg} \mathrm{m}^{-2}$ as a 1 -h infusion every 3 weeks. Patients in arm B received oxaliplatin $85 \mathrm{mg} \mathrm{m}^{-2}$ as a 1-h infusion and docetaxel $50 \mathrm{mg} \mathrm{m}^{-2}$ as a 1 -h infusion every 2 weeks. Antiemetic prophylaxis was given according to guidelines. While receiving cisplatin, patients were hydrated with up to $3000 \mathrm{ml}$ of normal saline. Treatment in arm A was continued up to six cycles and in arm B up to 8 cycles or until disease progression, unacceptable toxicity, patient's refusal or physician's decision. The addition of bevacizumab was allowed at the investigators' discretion. Patients were additionally stratified according to the planned use of bevacizumab.

The dose of docetaxel was reduced by $25 \%$ for diarrhoea and mucositis (exceeding National Cancer Institute Common Toxicity Criteria (NCI-CTC) grade 2) at first occurrence and by $50 \%$ at second occurrence. For grade 4 neutropenia/ thrombocytopenia or febrile neutropenia, the dose of the chemotherapy was reduced by $25 \%$ at first occurrence and $50 \%$ at second occurrence, and treatment was terminated by further occurrence. Cisplatin was discontinued for NCI-CTC grade 2 or worse renal toxicity. Oxaliplatin dose modifications were performed as described previously (Louvet et al, 2002).

Toxicity assessment. Toxicities were graded according to NCICTC version 3. Peripheral sensitive neuropathy was graded according to an oxaliplatin-specific scale as described previously (Caussanel et al, 1990)

Evaluation of efficacy outcomes. Responses were classified according to RECIST. Computed tomography or magnetic resonance imaging scans of target areas were performed before the start of the treatment and were repeated every 8 weeks in both arms. Patients who discontinued the study were evaluated every 2 months. Time to progression (TTP) was measured from the date of random assignment until disease progression. Overall survival (OS) was measured from the date of random assignment until death of any cause.

Statistical analysis. The primary end point was response rate according to RECIST 1.0 (Fisher's exact test). Secondary end points were toxicity ( $P$ for trend test), TTP (log-rank test), and OS (logrank test). Survival data were calculated using the Kaplan-Meier method on the intent-to-treat (ITT) population, which was predefined as all randomly assigned patients with NSCLC (efficacy population). The safety analysis included all patients who received chemotherapy (safety population). According to Simons optimal two-stage design for clinical trials, calculated sample size with the assumption of a lower response rate of $30 \%$ and a difference of $15 \%$ was 81 . Expecting a drop-off at a rate of $\sim 10 \%$, we decided to enrol 88 patients in total.

\section{RESULTS}

Patients. Between September 2008 and October 2010, a total of 88 patients (arm A, 43 patients; arm B, 45 patients) were recruited from 13 centres in Germany. Two patients were excluded from the efficacy population because of ineligible diseases (one patient with metastatic urothelial carcinoma of the urinary bladder and another with a mediastinal germline tumour). Therefore, 86 patients (arm A, 43 patients; arm B, 43 patients) were eligible for the efficacy analysis on an ITT basis. Overall, 87 patients were evaluable for the safety analysis. Fifteen patients, 7 patients in arm $\mathrm{A}$ and 8 patients in arm $\mathrm{B}$, received additionally bevacizumab.

The two groups were well balanced for pretreatment characteristics (Table 1) except for sex, with the proportion of female patients being $48.8 \%$ in arm $\mathrm{A}$ and $62.8 \%$ in arm B 
Table 1. Patient characteristics

\begin{tabular}{|c|c|c|c|c|}
\hline & \multicolumn{2}{|c|}{ Cis/Doc $(n=43)$} & \multicolumn{2}{|c|}{ Ox/Doc $(n=45)$} \\
\hline & $\begin{array}{l}\text { No. of } \\
\text { patients }\end{array}$ & $\%$ & $\begin{array}{l}\text { No. of } \\
\text { patients }\end{array}$ & $\%$ \\
\hline Total no. of patients & 43 & 48.9 & 45 & 51.1 \\
\hline \multicolumn{5}{|l|}{ Age } \\
\hline $\begin{array}{l}\text { Median } \\
\text { Range }\end{array}$ & $\begin{array}{c}65 \\
47-86\end{array}$ & & $\begin{array}{c}65 \\
39-82\end{array}$ & \\
\hline \multicolumn{5}{|l|}{ Gender } \\
\hline $\begin{array}{l}\text { Male } \\
\text { Female }\end{array}$ & $\begin{array}{l}21 \\
22\end{array}$ & $\begin{array}{l}48.8 \\
51.2\end{array}$ & $\begin{array}{l}28 \\
17\end{array}$ & $\begin{array}{l}62.2 \\
37.8\end{array}$ \\
\hline \multicolumn{5}{|l|}{ ECOG } \\
\hline $\begin{array}{l}0-1 \\
2\end{array}$ & $\begin{array}{c}40 \\
3\end{array}$ & $\begin{array}{r}93.0 \\
7.0\end{array}$ & $\begin{array}{c}40 \\
5\end{array}$ & $\begin{array}{l}88.9 \\
11.3\end{array}$ \\
\hline \multicolumn{5}{|c|}{ Histological subtype } \\
\hline $\begin{array}{l}\text { Squamous cell } \\
\text { Adenocarcinoma } \\
\text { Other }\end{array}$ & $\begin{array}{c}10 \\
29 \\
4\end{array}$ & $\begin{array}{r}23.3 \\
67.4 \\
9.3\end{array}$ & $\begin{array}{c}11 \\
26 \\
8\end{array}$ & $\begin{array}{l}24.4 \\
57.8 \\
17.8\end{array}$ \\
\hline \multicolumn{5}{|l|}{ Stage } \\
\hline $\begin{array}{l}\text { IIIB } \\
\text { IV }\end{array}$ & $\begin{array}{c}3 \\
40\end{array}$ & $\begin{array}{r}7.0 \\
93.0\end{array}$ & $\begin{array}{c}2 \\
43\end{array}$ & $\begin{array}{r}4.4 \\
95.6\end{array}$ \\
\hline \multicolumn{5}{|c|}{ Number of involved organs } \\
\hline $\begin{array}{l}\leqslant 1 \\
2 \\
\geqslant 3 \\
\text { Bevacizumab }\end{array}$ & $\begin{array}{l}19 \\
15 \\
9 \\
7\end{array}$ & $\begin{array}{l}44.2 \\
34.9 \\
20.9 \\
16.3\end{array}$ & $\begin{array}{c}15 \\
19 \\
11 \\
8\end{array}$ & $\begin{array}{l}33.3 \\
42.2 \\
24.4 \\
17.8\end{array}$ \\
\hline $\begin{array}{l}\text { Abbreviations: Cis/Doc } \\
\text { Eastern Cooperative Ond }\end{array}$ & $\begin{array}{l}\text { atin/docetaxel; } \\
\text { Group. }\end{array}$ & $\mathrm{Oc}=\mathrm{c}$ & atin/docetaxe & $O G=$ \\
\hline
\end{tabular}

(not significant). For both groups, median age was 65 years and median Eastern Cooperative Oncology Group performance status was 1. The majority (94.2\%) of the patients had stage IV (metastatic) disease (arm A, 93\%; arm B, 95.3\%) and 61.2\% had adenocarcinoma (arm A, 65.1\%; arm B, 58.1\%).

Safety and toxicity. The overall median treatment duration was 3.5 months (range, 0.2-6.3 months), with 3.3 months for arm A and 3.6 months for arm B. The median cumulative docetaxel dose per patient was $280 \mathrm{mg} \mathrm{m}^{-2}$ without difference in the treatment arms (270 vs $290 \mathrm{mg} \mathrm{m}^{-2}$ ). The median cumulative doses per patient for cisplatin and oxaliplatin were 340 and $350 \mathrm{mg} \mathrm{m}^{-2}$, respectively.

Overall, 87 patients were assessable for toxicity (Table 2). The treatment was generally well tolerated, and the incidence of grade 3 to 4 toxicities was relatively low in the two treatment arms. There were no remarkable differences in the incidence of anaemia, thrombocytopenia, nausea, emesis, infections and peripheral sensory neuropathy between the treatment arms. However, significantly fewer patients experienced any grade leukopenia (84\% vs $61 \%, P=0.03$ ) or grade $3 / 4$ leukopenia ( $44 \%$ vs $14 \%$, $P=0.002)$ and neutropenia (56\% vs 27\%, $P=0.0091)$ after treatment with $\mathrm{Ox} / \mathrm{Doc}$ as compared with Cis/Doc. Furthermore, the rates of complete alopecia $(76 \%$ vs $27 \%, P<0.0001)$ and any grade renal function impairment $(56 \%$ vs $11 \%, P<0.0001)$ or fatigue $(81 \%$ vs $59 \%, P=0.0344)$ were significantly higher in cisplatin-treated patients. Grade 3/4 infections had a strong trend to occur more frequently with Cis/Doc ( $26 \%$ vs $9 \%, P=0.0507)$.
Serious adverse events considered at least possibly related to the treatment were observed in $61 \%$ of patients treated with Cis/Doc and in $45 \%$ of patients treated with $\mathrm{Ox} / \mathrm{Doc}$ (no significant difference).

Treatment delays occurred in $26(60.5 \%)$ of 43 patients in arm A and $27(61.4 \%)$ of 44 patients in the arm B (no difference). Dose reductions of any drug were required in $16(37.2 \%)$ patients treated with Cis/Doc and in $12(27.3 \%)$ patients treated with Ox/Doc.

Reasons for treatment discontinuation in the Cis/Doc and Ox/ Doc arms, respectively, were disease progression $(23.3 \%$ vs $22.7 \%$ of patients), death (7.0\% vs $13.6 \%)$, toxicity ( $16.3 \%$ vs $2.3 \%$, $P=0.0298)$, consent withdrawal $(7.0 \%$ vs $11.4 \%)$ and other reasons (4.7\% vs $4.0 \%)$.

The need for G-SCF support was significant higher in arm A (12 vs 4 pts, $P=0.0335$ ), as was the use of NK-1 antagonists (40 vs 12 pts, $P=0.0001)$.

Similar rates for antibiotic treatment or transfusion were observed in both treatment arms.

Efficacy. The median follow-up time for surviving patients was 7 months. Sixty-six patients $(76.7 \%)$ had experienced progressive disease and 61 patients (70.9\%) had died. The response rate, which was the primary end point, was in favour of Cis/Doc, with $47 \%$ (95\% CI: $32.5-61.0 \%$ ) vs 28\% (95\% CI: 16.6-42.8\%) with Ox/Doc, but this did not reach statistical significance $(P=0.118$; Table 3$)$. There was no statistically significant difference in median OS and TTP with 11.6 vs 7.0 months $(P=0.102)$ and 6.3 vs 4.9 months $(P=0.111)$ with Cis/Doc and $\mathrm{Ox} / \mathrm{Doc}$, respectively, although the study was not powered to detect differences in survival (Figure 1). The 1-year survival rates were $32.5 \%$ (95\% CI: $20.4-47.6 \%$ ) with Cis/Doc and 18.6\% (95\% CI: 9.5-32.9\%) with Ox/Doc and were also not significantly different $(P=0.216)$.

In the univariate analysis, there was no difference in OS and TTP regarding different subgroups such as sex, age, performance status and use of bevacizumab, with the exception of histology; in squamous-cell carcinoma, OS was significantly prolonged compared with nonsquamous histology $(P=0.0448)$, especially in the patient group receiving cisplatin. This unexpected observation may have derived from the limited patient number.

In the multivariate analysis, histology (squamous $v s$ nonsquamous) and treatment (cisplatin $v s$ oxaliplatin) were independent prognostic parameters for OS and TTP, whereas the gender and the use of bevacizumab did not correlate with survival (data not shown).

\section{DISCUSSION}

Several noncomparative phase II studies have indicated that oxaliplatin doublets may represent an effective and well-tolerated first-line treatment for patients with advanced NSCLC (Monet et al, 2002; Franciosi et al, 2003; Kouroussis et al, 2003; Winegarden et al, 2004; Capuzzo et al, 2005; Raez et al, 2006; Früh et al, 2008; Mir et al, 2009; Radhakrishnan et al, 2009).

In a randomised setting, clinical efficacy of oxaliplatin doublets were similar to those with carboplatin in two phase II studies (Bidoli et al, 2007, gemcitabine combination; Scagliotti et al, 2005, pemetrexed combination) and had a more favourable toxicity profile. However, in one phase III trial (Weismann et al, 2011) comparing oxaliplatin/gemcitabine with carboplatin/paclitaxel, the incidence of adverse events exceeded the expected threshold, and hence the study was terminated early. Also, this trial showed similar efficacy for both treatment arms (response rates $15.2 \%$ vs 22.4\%, median OS 9.90 vs 9.24 months).

In direct comparison to cisplatin, three trials are reported, one in combination with gemcitabine ( $\mathrm{Li}$ et al, 2011) and two in combination with vinorelbine (Gao et al, 2005; Zhang et al, 2005), 
Table 2. Main toxicities according to the National Cancer Institute Common Toxicity Criteria version 3 (treatment-related toxicities)

All grades

Grade 3/4

\begin{tabular}{|c|c|c|c|c|c|c|c|c|c|c|}
\hline & \multicolumn{2}{|c|}{ Cis/Doc $(n=43)$} & \multicolumn{2}{|c|}{ Ox/Doc $(n=44)$} & & \multicolumn{2}{|c|}{ Cis/Doc $(n=43)$} & \multicolumn{2}{|c|}{ Ox/Doc $(n=44)$} & \multirow[b]{2}{*}{$P$-value } \\
\hline & No. & $\%$ & No. & $\%$ & $P$-value & No. & $\%$ & No. & $\%$ & \\
\hline \multicolumn{11}{|l|}{ Haematologic } \\
\hline Anaemia & 33 & 76.7 & 30 & 68.2 & NS & 1 & 2.3 & 5 & 11.4 & NS \\
\hline Leukopenia & 36 & 83.7 & 27 & 61.4 & 0.0300 & 19 & 44.2 & 6 & 13.6 & 0.0020 \\
\hline Neutropenia & 31 & 72.1 & 26 & 59.1 & NS & 24 & 55.8 & 12 & 27.3 & 0.0091 \\
\hline Thrombocytopenia & 14 & 32.6 & 7 & 15.9 & NS & 4 & 9.3 & 0 & 0 & 0.0554 \\
\hline
\end{tabular}

Gastrointestinal

\begin{tabular}{|l|l|l|}
\hline Nausea & 39 & 90.7 \\
Vomitting & 25 & 58.1 \\
Diarrhoea & 28 & 65.1 \\
Constipation & 12 & 27.9 \\
Stomatitis & 24 & 55.8 \\
\hline
\end{tabular}

Hepatic

\begin{tabular}{|l|r|r|r|r|r|}
\hline AST/ALT & 7 & 16.3 & 15 & 34.1 & NS \\
ALP & 7 & 16.3 & 9 & 20.5 & NS \\
\hline
\end{tabular}

\section{Neurologic}

\begin{tabular}{|c|c|c|c|c|c|c|c|c|c|c|}
\hline Neurosensory & 23 & 53.5 & 27 & 61.4 & NS & 1 & 2.3 & 2 & 4.5 & NS \\
\hline \multicolumn{11}{|l|}{ Others } \\
\hline Alopecia & 38 & 88.4 & 31 & 70.5 & NS & 33 & 76.4 & 12 & 27.3 & $>0.0001$ \\
\hline Fatigue & 35 & 81.4 & 26 & 59.1 & 0.0344 & 9 & 20.1 & 9 & 20.5 & NS \\
\hline Creatinine & 24 & 55.8 & 5 & 11.4 & $>0.0001$ & 1 & 2.3 & 1 & 2.3 & NS \\
\hline Weight loss & 18 & 41.9 & 12 & 27.3 & NS & 1 & 2.3 & 0 & 0 & NS \\
\hline Infection & 18 & 41.9 & 13 & 29.5 & NS & 11 & 25.6 & 4 & 9.1 & 0.0507 \\
\hline Fever & 10 & 23.6 & 8 & 18.2 & NS & 0 & 0 & 0 & 0 & NS \\
\hline
\end{tabular}

Abbreviations: $\mathrm{Cis} / \mathrm{Doc}=$ cisplatin/docetaxel; Ox/Doc =oxaliplatin/docetaxel; AST/ALT = aspartate aminotransferase/alanine aminotransferase; $\mathrm{ALP}=$ alkaline phosphatase; $\mathrm{NS}=$ not significant. Bold numbers indicate statistically significant differences.

all in Asian patients (and full publications only in Chinese), and hence our study is the only randomised trial conducted in a western patient population.

The motivation to conduct a trial replacing cisplatin by oxaliplatin includes the assumption that oxaliplatin is better tolerated than cisplatin. In this context, one may question the combination of two potential neurotoxic drugs in our trial. However, the feasibility of the combination of docetaxel and oxaliplatin was intensively explored by our group in multiple trials in advanced or metastatic gastric cancer and was found to be safe and tolerable, particularly with respect to neurotoxicity. In two phase III trials (one of them of our group), oxaliplatin at $85 \mathrm{mg} \mathrm{m}^{-2}$ every 2 weeks proved to be at least as effective as cisplatin at standard doses for oesophagogastric cancer (Cunningham et al, 2008; Al-Batran et al, 2008a). In a next step, we conducted a phase II study adding docetaxel $\left(50 \mathrm{mg} \mathrm{m}^{-2}\right.$ every 2 weeks) to our oxaliplatin-based doublet (FLO) (Al-Batran et al, 2008b). Although the observed toxicity was higher than known from the two-drug regimen, the treatment was feasible and generally well tolerated. Especially, the neurotoxicity was lower than expected, with higher-grade neurosensory toxicity rate of $9.3 \%$. The results could be confirmed in multiple further trials (Al-Batran et al, 2011, 2012). Encouraged by these results in gastric cancer, we designed our current study using the present doses and the bi-weekly schedule in analogy to metastatic gastric cancer. The bi-weekly schedule used in our trial contains dose intensities of oxaliplatin $\left(85 \mathrm{mg} \mathrm{m}^{-2}\right.$ every 2 weeks equivalent to
Table 3. Response rate

\begin{tabular}{|c|c|c|c|c|}
\hline & \multicolumn{2}{|c|}{ Cis/Doc $(n=43)$} & \multicolumn{2}{|c|}{ Ox/Doc $(n=43)$} \\
\hline & No. & $\%$ & No. & $\%$ \\
\hline $\mathrm{RR}^{*}$ & 20 & $47^{a}$ & 12 & 28 \\
\hline CR & 1 & 2 & 1 & 2 \\
\hline $\begin{array}{l}\mathrm{PR} \\
\end{array}$ & 19 & 44 & 11 & 26 \\
\hline SD & 12 & 30 & 15 & 35 \\
\hline PD & 3 & 7 & 11 & 26 \\
\hline NE & 8 & 19 & 5 & 12 \\
\hline \multicolumn{5}{|c|}{$\begin{array}{l}\text { Abbreviations: } \quad \mathrm{Cis} / \mathrm{Doc}=\text { cisplatin/docetaxel; } \mathrm{Ox} / \mathrm{Doc}=\text { oxaliplatin/docetaxel; } \quad \mathrm{CR}= \\
\text { complete response; } \mathrm{PR}=\text { partial response; } \mathrm{RR}=\text { response rate; } \mathrm{SD}=\text { stable disease; } \mathrm{PD}= \\
\text { progressive disease; } \mathrm{NE}=\text { not evaluable. } \\
{ }^{\circ} \text { Cis/Doc: } 95 \% \mathrm{Cl} \text { (confidence interval): } 0.3251-0.6109 ; \mathrm{Ox} / \mathrm{Doc}: 95 \% \mathrm{Cl}: 0.1663-0.4281 .{ }^{*} \mathrm{P}- \\
\text { value }=0.1178 .\end{array}$} \\
\hline
\end{tabular}

$42.5 \mathrm{mg} \mathrm{m}^{-2}$ per week) and docetaxel $\left(50 \mathrm{mg} \mathrm{m}^{-2}\right.$ every 2 weeks equivalent to $25 \mathrm{mg} \mathrm{m}^{-2}$ per week) that are comparable to the doses generally recommended for 3 -week schedules (oxaliplatin $130 \mathrm{mg} \mathrm{m}^{-2}$ and docetaxel $75 \mathrm{mg} \mathrm{m}^{-2}$ ). However, it cannot be ruled out that the differences in toxicities and efficacy observed in our study might be related to an underdosing of these drugs or to this particular schedule. 

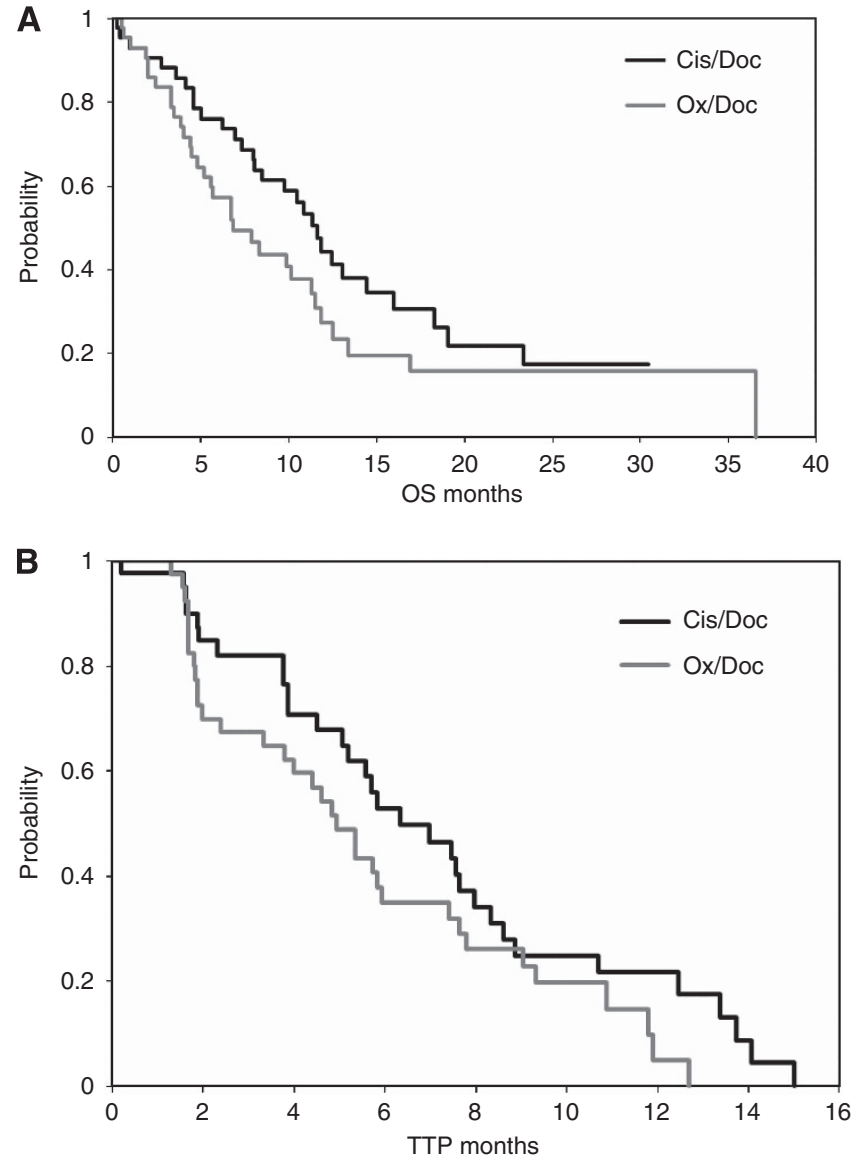

Figure 1. Survival analysis Kaplan-Meier curves for (A) OS and (B) TTP, assessed in the entire population. Median OS was 11.6 vs 7.0 months and median TTP 6.3 vs 4.9 months with cisplatin/docetaxel vs oxaliplatin/docetaxel, respectively.

In our multicentre study, we could demonstrate that the combination of oxaliplatin and docetaxel in the present dose and schedule is an active regimen in the first-line setting of metastatic NSCLC with an acceptable overall response rate of $28 \%$ (95\% CI: 16.6-42.8\%). The results are in line with other trials reporting response rates for oxaliplation doublets from 15 to $50 \%$. For example, Raez et al (2006) reported a response rate of 37\% (90\% CI: $22-55 \%)$ with oxaliplatin and docetaxel.

Although the response rate in our study was lower compared with the standard arm cisplatin/docetaxel with 47\% (95\% CI: $32.5-$ $61.1 \%)$, the difference was not statistically significant $(P=0.118)$. However, it demonstrates that the combination of cisplatin and docetaxel is one of the most potent regimens in NSCLC in terms of response.

Regarding TTP (4.9 vs 6.3 months) and OS (7.9 vs 11.6 months), there was a trend in favour of the cisplatin combination; however, the difference did not meet statistical significance $(P=0.127$ for TTP and $P=0.139$ for OS). The 1-year survival rate in the oxaliplatin arm was considerably lower (18.6\%, 95\% CI: 9.5-32.9\%) compared with other oxaliplatin-doublet trials. This may be influenced by the entire study population, as in the cisplatin arm the rate was only $32.5 \%$ (95\% CI: $20.4-47.6 \%$ ), which is in the lower range reported for cisplatin doublets. In the univariate and multivariate analyses, we observed a significant correlation of squamous-cell histology with improved overall survival. This could be a result of a higher efficacy of docetaxel in this histological subgroup, but this have to be interpreted with caution because of the limited patient number in our study.
Our study could show that toxicity is significantly reduced by the oxaliplatin doublet concerning nephrotoxicity (for all grades $P=0.0001)$ and severe grade leukopenia/neutropenia $(P=0.002$ and $P=0.009$ ). Furthermore treatment discontinuation because of toxicity occurred significantly less frequently with oxaliplatin/ docetaxel. Additionally, there was a trend towards a reduced infection rate $(P=0.0507)$, although this did not reach statistical significance. Patients with lung cancer often have infectious complications because of their comorbidities as well as cancerrelated disventilation of the lung regardless of the specific treatment. This may have contributed to similar infection rates in both arms despite reduction of leukopenia/neutropenia. Furthermore, patients with cisplatin/docetaxel received more frequently G-CSF support, and this additionally may have influenced the febrile neutropenia/infection rate.

Relevant side effects of cisplatin such as nausea, emesis and loss of appetite were not reduced by oxaliplatin. However, NK-1antagonists (aprepitant) were significantly more often used in cisplatin-treated patients and may have contributed to this result.

In addition, higher-grade fatigue and anaemia, which are often limiting factors in treatment, were not influenced by the use of oxaliplatin. Interestingly the incidence of sensoric neuropathy was not different in both treatment arms.

Our study shows that the oxaliplatin/docetaxel combination seems to have some activity in the first-line treatment of metastatic non-small lung cancer. However, the extent of activity observed in our trial does not justify further evaluation in a phase III setting. The study also shows that some reduction of toxicity was observed, mainly with respect to nephrotoxicity and leukopenia/neutropenia, as expected. However, this alone also does not justify further evaluation of oxaliplatin for particular groups such as patients unable to receive a cisplatin-based combination, because for this setting, especially in terms of reduction of non-haematological side effects, carboplatin is a well-established alternative for cisplatin, as shown in numerous randomised phase II and III studies. Furthermore, other standard options such as non-platinum doublets or single-agent chemotherapies are also acceptable alternatives for these patients.

\section{ACKNOWLEDGEMENTS}

This research was supported by a grant from Sanofi Aventis.

\section{REFERENCES}

Al-Batran SE, Hartmann JT, Hofheinz R, Homann N, Rethwisch V, Probst S, Stoehlmacher J, Clemens MR, Mahlberg R, Fritz M, Seipelt G, Sievert M, Pauligk C, Atmaca A, Jäger E (2008b) Biweekly fluorouracil, leucovorin, oxaliplatin, and docetaxel (FLOT) for patients with metastatic adenocarcinoma of the stomach or esophagogastric junction: a phase II trial of the Arbeitsgemeinschaft Internistische Onkologie. Ann Oncol 19(11): 1882-1887.

Al-Batran SE, Hartmann JT, Probst S, Schmalenberg H, Hollerbach S, Hofheinz R, Rethwisch V, Seipelt G, Homann N, Wilhelm G, Schuch G, Stoehlmacher J, Derigs HG, Hegewisch-Becker S, Grossmann J, Pauligk C, Atmaca A, Bokemeyer C, Knuth A, Jäger E (2008a) Phase III trial in metastatic gastroesophageal adenocarcinoma with fluorouracil, leucovorin plus either oxaliplatin or cisplatin: a study of the Arbeitsgemeinschaft Internistische Onkologie. J Clin Oncol 26(9): 1435-1442.

Al-Batran SE, Hofheinz R, Homann N, Illerhaus G, Martens UM, Stoehlmacher-Williams J, Schmalenberg H, Luley KB, Prasnikar N, Egger M, Probst S, Hartmann JT, Moehler MH, Arnold D, Fischbach W, Pauligk C, Moenig SP, Piso P, Jaeger E (2011) Defining two prognostic groups of metastatic gastric cancer: FLOT3 trial of the Arbeitsgemeinschaft Internistische Onkologie (AIO). J Clin Oncol 29: (suppl; abstr 4070). 
Al-Batran SE, Pauligk C, Homann N, Hartmann JT, Moehler M, Probst S, Rethwisch V, Stoehlmacher-Williams J, Prasnikar N, Hollerbach S, Bokemeyer C, Mahlberg R, Hofheinz RD, Luley K, Kullmann F, Jäger E (2012) The feasibility of triple-drug chemotherapy combination in older adult patients with oesophagogastric cancer: a randomised trial of the Arbeitsgemeinschaft Internistische Onkologie (FLOT65 + ). Eur J Cancer pii S0959-8049(12): 00750-00752.

Ardizzoni A, Boni L, Tiseo M, Fossella FV, Schiller JH, Paesmans M, Radosavljevic D, Paccagnella A, Zatloukal P, Mazzanti P, Bisset D, Rosell R. CISCA (CISplatin versus CArboplatin) Meta-analysis Group (2007) Cisplatin- versus carboplatin-based chemotherapy in first-line treatment of advanced non-small-cell lung cancer: an individual patient data metaanalysis. J Natl Cancer Inst 99(11): 847-857.

Bidoli $\mathrm{P}$, Zilembo N, Cortinovis D, Mariani L, Isa L, Aitini E, Cullurà D, Pari F, Nova P, Mancin M, Formisano B, Bajetta E (2007) Randomized phase II three-arm trial with three platinum-based doublets in metastatic nonsmall-cell lung cancer. an Italian Trials in Medical Oncology study. Ann Oncol 18(3): 461-467.

Cappuzzo F, Novello S, De Marinis F, Franciosi V, Maur M, Ceribelli A, Lorusso V, Barbieri F, Castaldini L, Crucitta E, Marini L, Bartolini S, Scagliotti GV, Crinò L (2005) Phase II study of gemcitabine plus oxaliplatin as first-line chemotherapy for advanced non-small-cell lung cancer. Br J Cancer 93(1): 29-34.

Caussanel JP, Lévi F, Brienza S, Misset JL, Itzhaki M, Adam R, Milano G, Hecquet B, Mathé G (1990) Phase I trial of 5-day continuous venous infusion of oxaliplatin at circadian rhythm-modulated rate compared with constant rate. J Natl Cancer Inst 82: 1046-1050.

Cunningham D, Starling N, Rao S, Iveson T, Nicolson M, Coxon F, Middleton G, Daniel F, Oates J, Norman AR (2008) Capecitabine and oxaliplatin for advanced esophagogastric cancer. N Engl J Med 358(1): 36-46.

Fossella F, Pereira JR, von Pawel J, Pluzanska A, Gorbounova V, Kaukel E, Mattson KV, Ramlau R, Szczesna A, Fidias P, Millward M, Belani CP (2003) Randomized, multinational, phase III study of docetaxel plus platinum combinations versus vinorelbine plus cisplatin for advanced non-small-cell lung cancer: the TAX 326 study group. J Clin Oncol 21(16): 3016-3024.

Franciosi V, Barbieri R, Aitini E, Vasini G, Cacciani GC, Capra R, Camisa R, Cascinu S (2003) Gemcitabine and oxaliplatin: a safe and active regimen in poor prognosis advanced non-small cell lung cancer patients. Lung Cancer 41(1): 101-106.

Früh M, Gillessen S, Cerny T, Demmer R, D’Addario G (2008) Two-weekly gemcitabine fixed dose rate and oxaliplatin combination chemotherapy for advanced non-small-cell lung cancer. Lung Cancer 62(3): 344-350.

Gao JF, Zhang XH, Wang J, Rao ZG, Zhu YZ, Ou WL, Zhang BC, Du GZ (2005) [Efficacy of NO regimen and NP regimen on advanced non-small cell lung cancer: a prospective randomized trial]. Ai Zheng 24(8): 990-993.

Kouroussis C, Agelaki S, Mavroudis D, Kakolyris S, Androulakis N, Kalbakis K, Souglakos J, Mallas K, Bozionelou V, Pallis A, Adamtziki H, Georgoulias V (2003) A dose escalation study of docetaxel and oxaliplatin combination in patients with metastatic breast and non-small cell lung cancer. Anticancer Res 23(1B): 785-791.

Li Z, Hou M, Wang H, Wang Z (2011) A randomized study of gemcitabine plus oxaliplatin versus gemcitabine plus cisplatin as the 1st line chemotherapy for advanced non-small cell lung cancer in elderly patients. Zhongguo Fei Ai Za Zhi 14(7): 588-592.

Louvet C, André T, Tigaud JM, Gamelin E, Douillard JY, Brunet R, François E, Jacob JH, Levoir D, Taamma A, Rougier P, Cvitkovic E, de Gramont A (2002) Phase II study of oxaliplatin, fluorouracil, and folinic acid in locally advanced or metastatic gastric cancer patients. J Clin Oncol 20: 4543-4548.

Mir O, Alexandre J, Ropert S, Montheil V, Martin I, Durand JP, Goldwasser F (2009) Vinorelbine and oxaliplatin in stage IV nonsmall cell lung cancer patients unfit for cisplatin: a single-center experience. Anticancer Drugs 20(2): 105-108.

Mok TS, Wu YL, Thongprasert S, Yang CH, Chu DT, Saijo N, Sunpaweravong P, Han B, Margono B, Ichinose Y, Nishiwaki Y, Ohe Y, Yang JJ, Chewaskulyong B, Jiang H, Duffield EL, Watkins CL, Armour AA, Fukuoka M (2009) Gefitinib or carboplatin-paclitaxel in pulmonary adenocarcinoma. N Engl J Med 361(10): 947-957.

Monnet I, de CH, Soulié P, Saltiel-Voisin S, Bekradda M, Saltiel JC, Brain E, Rixe O, Yataghene Y, Misset JL, Cvitkovic E (2002) Oxaliplatin plus vinorelbine in advanced non-small-cell lung cancer: final results of a multicenter phase II study. Ann Oncol 13(1): 103-107.

Radhakrishnan A, Bitran JD, Milton DT, Tolzien K, Hallmeyer S, Nabhan C (2009) Docetaxel and oxaliplatin as first-line therapy for advanced non-small cell lung cancer: a phase II trial. J Chemother 21(4): 439-444.

Raez LE, Santos ES, Lopes G, Rosado MF, Negret LM, Rocha-Lima C, Tolba K, Farfan N, Hamilton-Nelson K, Silva O, Roman E (2006) Efficacy and safety of oxaliplatin and docetaxel in patients with locally advanced and metastatic non-small-cell lung cancer (NSCLC). Lung Cancer 53(3): 347-35317.

Rosell R, Gatzemeier U, Betticher DC, Keppler U, Macha HN, Pirker R, Berthet P, Breau JL, Lianes P, Nicholson M, Ardizzoni A, Chemaissani A, Bogaerts J, Gallant G (2002) Phase III randomised trial comparing paclitaxel/carboplatin with paclitaxel/cisplatin in patients with advanced non-small-cell lung cancer: a cooperative multinational trial. Ann Oncol 13(10): 1539-1549.

Scagliotti GV, Kortsik C, Dark GG, Price A, Manegold C, Rosell R, O’Brien M, Peterson PM, Castellano D, Selvaggi G, Novello S, Blatter J, Kayitalire L, Crino L, Paz-Ares L (2005) Pemetrexed combined with oxaliplatin or carboplatin as first-line treatment in advanced non-small cell lung cancer: a multicenter, randomized, phase II trial. Clin Cancer Res 11(2 Pt 1): 690-696.

Weissman CH, Reynolds CH, Neubauer MA, Pritchard S, Kobina S, Asmar L (2011) A phase III randomized trial of gemcitabine-oxaliplatin versus carboplatin-paclitaxel as first-line therapy in patients with advanced nonsmall cell lung cancer. J Thorac Oncol 6(2): 358-364.

Winegarden JD, Mauer AM, Otterson GA, Rudin CM, Villalona-Calero MA, Lanzotti VJ, Szeto L, Kasza K, Hoffman PC, Vokes EE (2004) A phase II study of oxaliplatin and paclitaxel in patients with advanced non-smallcell lung cancer. Ann Oncol 15(6): 915-920.

Zhang XR, Hou M, Sun JD, Gao JF, Zhu YZ, Peng DW, Zhang YP, Chen J, Yang JL, Liang J, Wang PH, Chu DT (2005) A randomized trial comparing oxaliplatin plus vinorelbine versus cisplatin plus vinorelbine for the treatment of patients with advanced non-small-cell lung cancer. Zhonghua Zhong Liu Za Zhi 27(12): 743-746.

This work is published under the standard license to publish agreement. After 12 months the work will become freely available and the license terms will switch to a Creative Commons AttributionNonCommercial-Share Alike 3.0 Unported License. 